\title{
The Core-Periphery Structure in the Yangtze River Delta: An Enterprise Linkage Perspective, 1978-2019
}

\author{
Jieying Yang, ${ }^{1}$ Jingxiang Zhang, ${ }^{1}$ Jiayi $L u,{ }^{2,3}$ and Dongqi Sun $\mathbb{D}^{2}$ \\ ${ }^{1}$ School of Architecture and Urban Planning, Nanjing University, Nanjing 210093, China \\ ${ }^{2}$ Key Laboratory of Regional Sustainable Development Modeling, \\ Institute of Geographic Sciences and Natural Resources Research, Chinese Academy of Science, Beijing 100101, China \\ ${ }^{3}$ College of Resources and Environment, University of Chinese Academy of Sciences, Beijing 100049, China \\ Correspondence should be addressed to Dongqi Sun; sundq@igsnrr.ac.cn
}

Received 20 April 2021; Revised 12 July 2021; Accepted 29 October 2021; Published 28 November 2021

Academic Editor: Marcus Aguiar

Copyright (c) 2021 Jieying Yang et al. This is an open access article distributed under the Creative Commons Attribution License, which permits unrestricted use, distribution, and reproduction in any medium, provided the original work is properly cited.

\begin{abstract}
Metropolitan areas are important for engaging in fierce global competition. Cities in metropolitan areas in China are generally characterized by a core-periphery structure. The Yangtze River Delta metropolitan area (YRD) is a national strategic region in which Shanghai, as a central city, drives the economic growth of hinterland cities. Exploring the spatiotemporal characteristics and influencing factors between the central city and its hinterland cities in the YRD can provide a basis for promoting regional development. Based on the headquarters-branches and enterprise investment data from 1978 to 2019, this study analyzes the spatiotemporal characteristics and influencing factors of enterprise linkages between Shanghai and its hinterland cities in the YRD. Our results reveal the following: (1) the headquarters-branch linkages between Shanghai and its hinterland cities manifest polarization characteristics, with different polarized characteristics among the three provinces; (2) the enterprise investment linkages between Shanghai and its hinterland cities are getting closer, but the key cities for investment in each province are different; (3) economic strength is a core factor that affects whether Shanghai establishes enterprise branches in its hinterland cities; and (4) the enterprise investment linkages between Shanghai and its hinterland cities depend on whether a city has a comparative advantage.
\end{abstract}

\section{Introduction}

With the rapid development of globalization and informatization, many cities have come to rely on infrastructure networks to form highly integrated metropolitan areas to address fierce global competition [1]. Metropolitan areas are basic geographical units that participate in global competition, and their development is of great significance to the sustained stability of the regional economy [2]. The links between cities are growing closer, city coordination has become a general method to promote economic development, and competitiveness has also become an important indicator of internationalization for measuring metropolitan areas [3]. As Scott points out, due to the increasing integration of cities in the world economy and emerging internal functional connections, these densely populated urbanized areas have become strategically crucial in the global economy [4].
Currently, many scholars point out that metropolitan areas have core-periphery structures, featuring a central city and hinterland cities, among which the central city plays the role of a "knowledge portal," connecting the hinterland cities to the global economic network. The central city's connection with the city inside the region is often closer than its connection with the city outside the region [5]. Diffusion from the central city to its hinterland cities is an intentional choice $[6,7]$. Understanding how the central city affects its hinterland cities and discussing its evolutionary laws and influencing factors are important tasks for promoting both the integrated development of metropolitan areas and regional economic development and have become an important part of the reform of the national economic system [8].

The Yangtze River Delta metropolitan area (YRD) is the largest metropolitan area in China, located in the eastern coastal area, with an outstanding location, strong economic 
basis, and well-developed infrastructural constructions. In 2016, the central government proposed "the Development Plan for the Yangtze River Delta Metropolitan Area," which clarified the central position of Shanghai in this area. In 2018, the State Council issued "Opinions on Establishing a New Mechanism for More Effective Regional Coordinated Development," which pointed out that the central city plays a vital role in promoting the high-quality development of metropolitan areas. Currently, the construction of the YRD has become a national strategy. To implement policies formulated by the central government, it is necessary to conduct further research on the spatial organizational relationships that characterize the area.

To study urban networks, many scholars judge the relationship between central and hinterland cities through the comparison of urban population and land area. However, with the development of globalization and information technology, the logic of the relationship between cities has replaced the location theory. The relationship between cities no longer depends solely on their own size, but more on the strength of their relationship. The research on urban relevance based on "flow space" provides ideas for analyzing the relationship between central and hinterland cities. As enterprise linkage data have easy access and are directional, they can better analyze core-periphery problems in metropolitan areas. Therefore, urban relationship research based on enterprise linkages has become one of the important means to understand the internal network analysis of metropolitan areas.

Although the city network research based on enterprise linkages has many advantages, it is currently based more on headquarters-branch enterprise linkage data and mostly focuses on the comparison between global city networks and city clusters. Research on the core and periphery structure is relatively scarce, and there is also a lack of systematic investigation into how the central city affects the spatial evolution of the periphery city. Due to difficulties in data acquisition, current research focusing on the internal evolution of metropolitan areas is mostly based on short-term data analysis. However, it takes a long time for the central city to spill over to the peripheral areas. Based on short-term analysis, it is difficult to fully and deeply analyze the central city's spread to peripheral cities.

Therefore, this study selected the YRD as an empirical area and analyzed its spatiotemporal characteristics and the factors influencing them from 1978 to 2019 . We focused on the following three issues: (1) the characteristics of the temporal and spatial evolution of the enterprise linkages between Shanghai and its hinterland cities; (2) the factors influencing enterprise linkages between Shanghai and its hinterland cities; and (3) the possible core-peripheral mechanisms within the YRD.

\section{Literature Review}

Research on metropolitan areas is prevalent in the fields of urban geography and urban planning. Various theories have been advanced under its umbrella, such as the central place theory and the core-periphery theory. In the early stages of documentation, research often uses data such as city size, population, and GDP [9] to classify a city's hierarchical scale system to determine relationships between cities. This type of analysis focuses on the characteristics of the scale of the city [10] and cannot accurately reflect the strength of relationships between cities. In 1996, Castells proposed the concept of the space of flow, emphasizing the constructivist nature of cities [11]. To a certain extent, this concept overturned the traditional logic of regional analysis based on scale attributes, focusing more acutely on the strength of the connections between cities [12-14]. Since then, the space of flow theory has gradually replaced the central place theory, forming a new urban system paradigm [15].

Due to the difficulty of obtaining relational data between cities, scholars are committed to discovering relational data to represent the linkages between cities for empirical research [11]. Airline passenger data [16], railway networks [17], bus networks [18], telecommunication flows [19], Bluetooth data [20], knowledge collaboration networks $[21,22]$, and enterprise linkages [23, 24] have all become important means of providing new perspectives for research on urban networks at home and abroad. However, there are many limitations to these studies. For example, it is difficult for traffic data to distinguish the purpose of tourists' travel and the linkages between cities for the development of the tourism industry may be magnified as a result. Derudder et al. analyzed the infrastructure network in South Asia and found that a city located between two important transportation hubs may have an overestimated transportation connectivity. This may be the result of the layout of the transportation network rather than its real connectivity [25]. The measurement method of monitoring telecommunication flows and knowledge collaboration networks encounters difficulty in distinguishing the starting point from the ending point between cities [17]. This method focuses more on judging the hierarchical status of the city in the network structure [21].

International studies have shown that the essence of the city network is the economic network, and enterprises are the agents of the city network [26]. The enterprise linkage method is conceptually closest to the actual process of a city network [27]. The enterprise linkage data can solve the problem of direction attributes in the analysis of the coreperipheral structure. At the global level, some scholars have analyzed the global city network and its core-peripheral structure by using the headquarters-branch enterprise data of advanced producer services (APS) or multinational corporations. Taylor analyzed the distribution of 175 APS enterprises in 138 cities and explored the home region and outreach of the region on a global scale [26]. Derudder and Taylor used the data of APS enterprises to analyze 157 cities and to discern the core-periphery model [28]. At the regional scale, some scholars have compared and analyzed the differences between various metropolitan areas. Zilai and Tao compared the YRD and the Middle Reaches of the Yangtze River and analyzed the network connection patterns of the two metropolitan areas in the global and national systems [29]. Lu et al. compared the different effects of central cities on hinterland cities in the Beijing-Tianjin- 
Hebei region and the YRD [30]. However, only a few scholars have focused on the structural characteristics of metropolitan areas. Salder takes the Greater Birmingham area as an example to explore the relationship between the enterprise network and the city network, and in doing so, strengthened our understanding of the core-periphery relationship [31]. Yeh et al. and Zhang et al. employed the connection analysis of APS companies to conclude that the Pearl River Delta has a hierarchical structure with Guangzhou and Shenzhen as the central cities and used social network analysis to describe the characteristics of the cities [32, 33].

In general, research at the global level regards the metropolitan area as a whole and lacks any discussion of internal urban network structures. Regional-level research focuses on the analysis of urban hierarchical structures and character descriptions, and related studies mostly use shortterm headquarters-branch data, lacking the support of longterm continuous data and ignoring the important indicator presented by enterprise investment data. The incompetency of data is not conducive to systematically explaining the evolution of metropolitan areas.

Currently, studies have limited explanatory power when it comes to the analysis of long-term spatiotemporal characteristics and their influencing factors amid the core-periphery structure of the YRD. Therefore, based on the perspective of enterprise linkages, this study uses headquarters-branch and enterprise investment data from 1978 to 2019 in the YRD to analyze its spatiotemporal characteristics and utilizes pool OLS models to explore the influencing factors of the connection between Shanghai and its hinterland cities. A complete and continuous data foundation can provide support for long-term evolution analysis and promote our understanding of diffusion characteristics between central and hinterland cities in the region [34].

\section{Materials and Methods}

3.1. Study Area. The YRD is a highly urbanized metropolitan area and one of the largest financial hubs in China. Over the years, the YRD has undergone tremendous changes in scope. In 2010, the "Regional Plan for the Yangtze River Delta Region (2010-2015)" proposed that the YRD include 16 cities. In 2016, the "Development Plan for the Yangtze River Delta Metropolitan Area" stated that the YRD, in fact, includes 26 cities. In 2019, the "Outline of the Yangtze River Delta Regional Integrated Development Plan" updated that number to 41 . These include one province-level city (Shanghai) and three provinces (Jiangsu, Zhejiang, and Anhui Provinces), comprising a total of 40 cities. Shanghai is the central city, and the remaining 40 are hinterland cities. These hinterland cities include 13 prefecture-level cities in Jiangsu Province: Nanjing, Wuxi, Xuzhou, Changzhou, Suzhou, Nantong, Lianyungang, Huai'an, Yancheng, Yangzhou, Zhenjiang, Taizhou, and Suqian; 11 prefecturelevel cities in Zhejiang Province: Hangzhou, Ningbo, Wenzhou, Jiaxing, Huzhou, Shaoxing, Jinhua, Quzhou,
Zhoushan, Taizhou, and Lishui; and 16 prefecture-level cities in Anhui Province: Hefei, Wuhu, Bengbu, Huainan, Maanshan, Huaibei, Tongling, Anqing, Huangshan, Chuzhou, Fuyang, Suqian, Lu'an, Bozhou, Chizhou, and Xuancheng. This study adopts these 41 cities as its research scope (Figure 1), and the period under study begins in 1978.

3.2. Basic Idea and Data Sources. According to the coreperiphery theory, metropolitan areas include the central city and the hinterland cities. Headquarters-branch enterprises build organizational connections between the central city and the hinterland cities; if a headquarters' enterprise is in Shanghai and its branch enterprise is in a hinterland city, this is regarded as a headquarters-branch enterprise linkage. Enterprise investment refers to the behavior of enterprises that are located in the central city and invest in hinterland cities; if an enterprise located in Shanghai is the investor and the invested enterprise is located in a hinterland city, this will be regarded as an enterprise investment linkage (Figure 2).

The spatiotemporal characteristics of the regional coreperiphery structure and its influencing factors are complex. To start to make sense of this complexity, we conducted the following processes: (1) analyzing the spatiotemporal characteristics of the enterprise linkages between the central city and the hinterland cities and (2) discussing the factors influencing the establishment of enterprise linkages between the central city and hinterland cities.

The data source for this research is the enterprise registration information of the State Administration for Industry and Commerce (http://www.gsxt.gov.cn). It contains data on the number of headquarters-branch enterprises and the amount of enterprise investment between cities, from 1978 to 2019. We organized the data with Shanghai as the enterprise headquarters/investor and the 40 hinterland cities as the enterprise branches/investees. This study analyzes the spatiotemporal evolution of the dynamics between Shanghai and other cities in the YRD through the enterprise linkages method to reflect Shanghai's connection with other cities. Based on regression analysis, we inferred the factors that influence Shanghai's establishment of enterprise linkages with other cities.

According to Wei, globalization, marketization, and other factors have influenced China's regional economic development patterns [35]. We divided the period from 1978 to 2019 into four stages. China began to reform and open up in 1978, and it was not until 1992 that the socialist market economy system was initially established. Therefore, we set the first stage from 1978 to 1990, the period of the commodity economy, and the second stage from 1990 to 2000, the period of marketization. China's accession to the World Trade Organization in 2001 rendered it more closely connected to the world. Therefore, we marked the third stage from 2000 to 2010, the period of globalization. The last period was marked from 2011 to 2019. At this stage of the financial crisis and the adjustment of the global economic structure, the focus of China's economic development gradually turned to localization. 


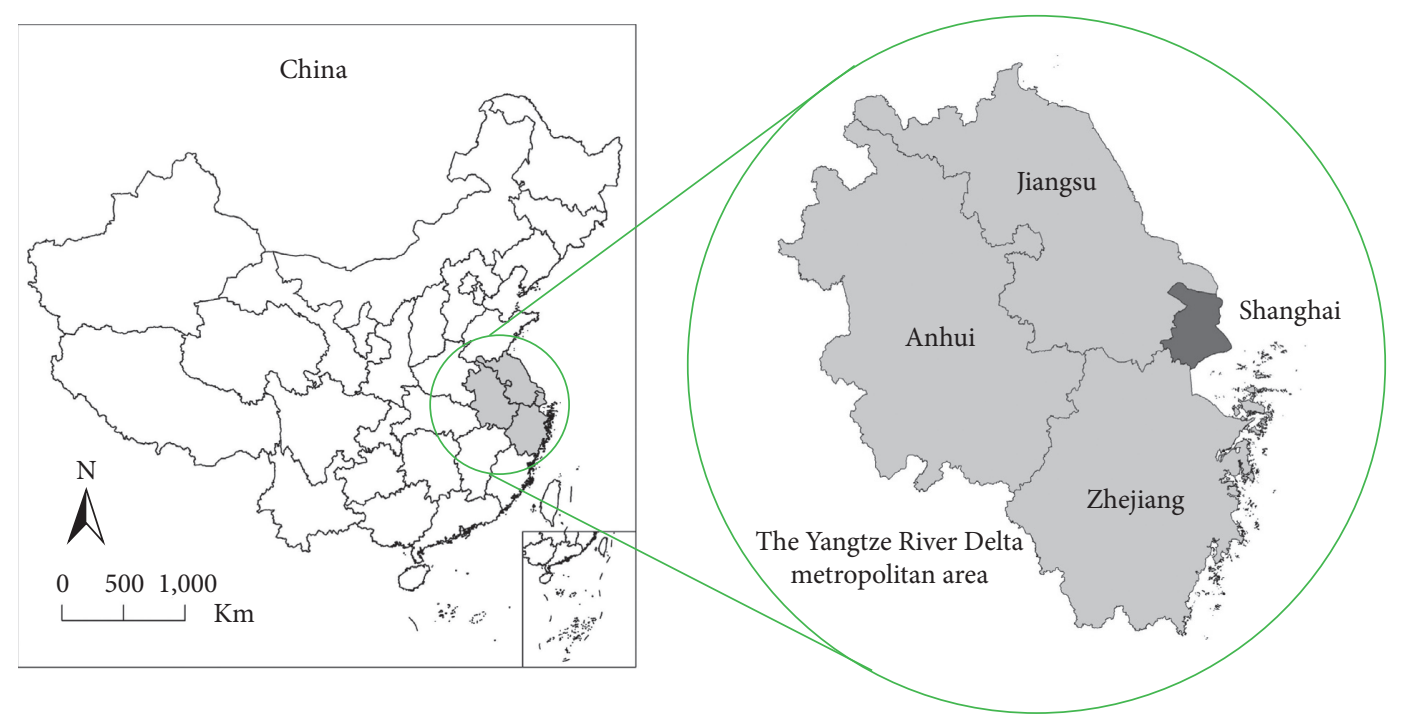

Figure 1: Map of the study area.

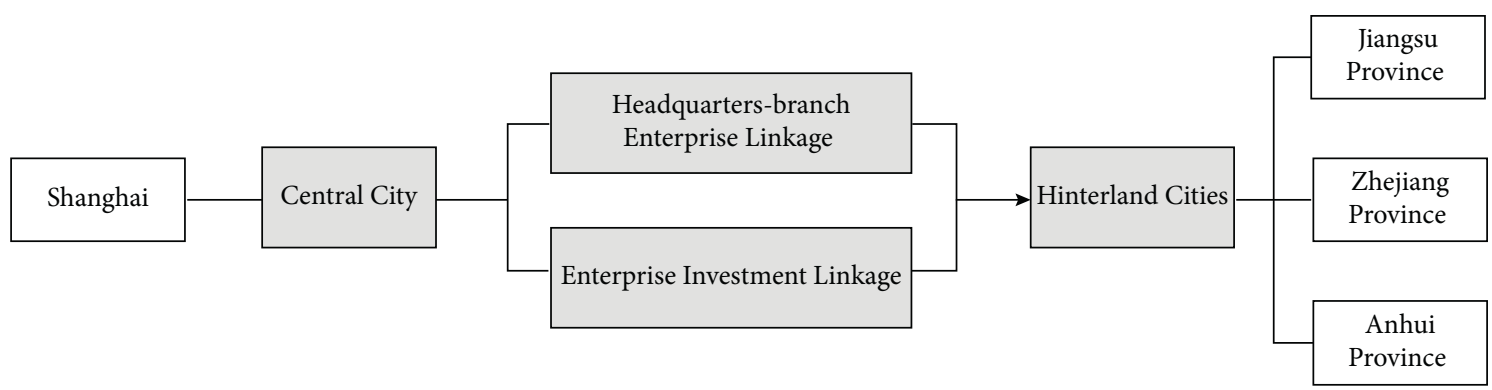

FIgURE 2: Enterprise linkages between the central city and hinterland cities.

3.3. Research Method and Influencing Factors. This article focuses on a comparative study of Shanghai's influencing factors in different provinces from 1978 to 2019 . Through the rationality test, the test results based on $R^{2}$ are all greater than 0.88 , this paper believes that the pool OLS model is suitable for analyzing Shanghai's influence factors on other hinterland cities.

Drawing on the practices observed in the previous literature [36-39] and combining them with the actual situation, we selected 10 indicators that have potentially impacted Shanghai's enterprise linkages in terms of capital input, labor input, urbanization, and level of industrialization (Table 1). The formula for the regression model is as follows:

$$
\begin{aligned}
Y_{i}= & \beta_{0}+\beta_{1} \ln \mathrm{FAI}_{i}+\beta_{2} \ln \mathrm{LR}_{i}+\beta_{3} \ln \mathrm{UR}_{i}+\beta_{4} \ln \mathrm{IDU}_{i} \\
& +\beta_{5} \ln \mathrm{FRE}_{i}+\beta_{6} \ln \mathrm{DP}_{i}+\beta_{7} \ln \mathrm{PD}_{i}+\beta_{8} \ln \mathrm{CGP}_{i} \\
& +\beta_{9} \ln \mathrm{HM}_{i}+\beta_{10} \ln \mathrm{TS}_{i}+\varepsilon_{i}(i=1, \ldots, n)
\end{aligned}
$$

where $Y_{i}$ is the number of enterprise linkages established between city $i$ and Shanghai. (1) $\mathrm{FAI}_{i}$ refers to the capital input. Capital inputs can provide support for the development of enterprises. This study uses per capita investment in fixed assets to measure capital inputs. (2) $L_{i}$ refers to the labor input. Sufficient labor provides the necessary production factors for the development of enterprises and creates conditions for them to expand the scale of the market and form capital accumulation. This study takes the number of employees in each city to measure the input of urban labor. (3) $\mathrm{UR}_{i}$ refers to the urbanization. The ratio of the nonagricultural population to the total population is taken to indicate the level of urbanization. (4) $\mathrm{IDU}_{i}$ represents the level of industrialization. The level of industrialization is the ratio of the output value of the secondary industry to the total output value. (5) $\mathrm{FRE}_{i}$ refers to the marketization. The level of marketization refers to the degree to which the market plays a role in resource allocation. The higher the degree of marketization, the higher the degree of openness of the city. Since it is difficult to obtain complete indicators for state-owned enterprises over a long period of time, this study uses the ratio of fiscal budget revenue to fiscal budget expenditure indicating the level of marketization [40]. (6) $\mathrm{DP}_{i}$ refers to the capital status. Capital status indicates the wealth of the city, and the per capita savings deposit balance of urban and rural residents is used to find a city's capital status. (7) $\mathrm{PD}_{i}$ refers to the labor abundance. Labor abundance indicates the abundance of the population, and this study uses population density to measure it. (8) $\mathrm{CGP}_{i}$ refers to the market capacity. Market capacity represents the level of consumption in a city, which is determined by the total number of retail sales of consumer goods per capita. (9) $\mathrm{HM}_{i}$ 
TABLE 1: Regression variables and representational meaning.

\begin{tabular}{lrc}
\hline Independent variables & Interpretation of independent variables (unit of measurement) & Representational meaning \\
\hline FAI & Per capita investment in fixed assets (yuan/person) & Capital input \\
LR & Number of employees (ten thousand people) & Labor input \\
UR & Ratio of nonagricultural population (\%) & Urbanization \\
IDU & Ratio of the output value of the secondary industry in the total output value (\%) & Industrialization level \\
FRE & Ratio of fiscal budget revenue to fiscal budget expenditure & Marketization \\
DP & Per capita savings deposit balance of urban and rural residents (yuan/person) & Capital status \\
PD & The population density (person/km ${ }^{2}$ ) & Labor abundance \\
CGP & Total retail sales of consumer goods per capita (yuan/person) & Market capacity \\
HM & Highway mileage (km) & Traffic accessibility \\
TS & Number of fixed telephone users (ten thousand households) & Communication facility status \\
\hline
\end{tabular}

refers to the traffic accessibility. The level of traffic accessibility is related to transportation costs. Theories in new economic geography dictate that underdeveloped areas will lead to high transportation costs due to backward transportation conditions. The highway mileage in the city was used as a measurement indicator. (10) $\mathrm{TS}_{i}$ represents communication facility status. The status of communication facilities is part of infrastructure construction, which can help companies convert internal costs into social public costs. This study analyzed the number of fixed telephone users. $\beta_{1} \sim \beta_{10}$ are the regression coefficients, $\varepsilon$ is the error disturbance term, and $n$ is the number of cities in the study area. The results of the White test and Variance Inflation Factor (VIF) test indicate that the multiple linear regression has no heteroscedasticity and multicollinearity problems.

The data sources for regression analysis include the yearbooks, statistical yearbooks, or statistical bulletins of 40 cities in the YRD from 1978 to 2019, such as "Nanjing Statistical Yearbook (1978-2019)," "Hangzhou Statistical Yearbook (1978-2019)," and "Hefei Statistical Yearbook (1978-2019)."

\section{Results and Discussion}

\subsection{Spatiotemporal Characteristics of Enterprise Linkages in the YRD}

4.1.1. Spatiotemporal Characteristics of Headquarters-Branch Enterprise Linkages. In general, Shanghai enterprises have obvious polarization characteristics in the establishment of branch companies in hinterland cities and the gradient of hinterland cities is becoming increasingly obvious (Figure 3, Tables 2-4). In terms of different provinces, Shanghai has different polarization characteristics among the three provinces. (1) The headquarters-branch enterprise linkages in Jiangsu Province have "dual polarization" characteristics. Suzhou and Nanjing are the two cities with the most branches, and the proportion of their enterprise branches in Jiangsu Province continues to increase. Specifically, from 1978 to 2019, the total proportion of the two cities' branches in Jiangsu Province increased from $18.18 \%$ to $50.74 \%$. Among them, the proportion of branches in Suzhou maintained a steady growth and the number of enterprise branches in Suzhou and Nanjing exhibited a widening trend. (2) The number of enterprise branches in Zhejiang Province is characterized by a dynamic of "core replacement." From 1992 to 2019, the ratio of Hangzhou's enterprise branches to the total number of branches in Zhejiang increased from $19.44 \%$ to $34.37 \%$, while in Ningbo, it dropped from $36.11 \%$ to $21.41 \%$. Hangzhou's core position has emerged, gradually replacing Ningbo as the city with the most branches. (3) The headquarters-branch enterprise linkages in Anhui Province exhibit significant "single-point polarization" characteristics. From 1992 to 2019, the proportion of the total number of branches in Hefei increased rapidly, from $17.65 \%$ to $43.30 \%$. As the second-largest city in Anhui, Wuhu's proportion of the total number of enterprise branches in the period from 1992 to 2019 gradually decreased from $17.65 \%$ to $8.78 \%$.

In terms of time, we have the following: (1) During the period of commodity economy, the establishment of enterprise branches was characterized by neighboring effects. Cities close to Shanghai were prioritized for the establishment of enterprise branches. Anhui Province is far from Shanghai. Compared with the Jiangsu and Zhejiang Provinces, there were fewer branches in the cities of Anhui. (2) During marketization, enterprise branches were concentrated in the three provincial capital cities, and the status of provincial capital cities was prominent. From 1992 to 2003, the growth rate of enterprise branches in provincial capital cities in their province was significantly higher than that in other periods and was also significantly higher than that of other cities in the same province. The proportion of Nanjing in Jiangsu Province increased by $8.27 \%$, while the proportion of Suzhou only increased by $1.61 \%$ and the proportion of Hangzhou in Zhejiang Province increased by 5.33\%, surpassing Ningbo to become the city with the largest number of branches in Zhejiang Province; the proportion of Hefei in Anhui Province also increased by $16.32 \%$. (3) During the period of globalization, Hefei's influence in the YRD increased and its primacy also increased significantly. From 2003 to 2009, although Jiangsu and Zhejiang Provinces still far surpassed Anhui Province in the total number of enterprise branches, at the city level, the gap between Hefei and Suzhou/Nanjing/Hangzhou decreased. Wuhu, the secondlargest city in Anhui Province, had a widening gap with Hefei. The gap widened from $17.84 \%$ in 2003 to $29.97 \%$ in 2009. (4) During the localization period, the three major cities of Suzhou, Hangzhou, and Nanjing established their dominant positions, becoming the cities with the closest 


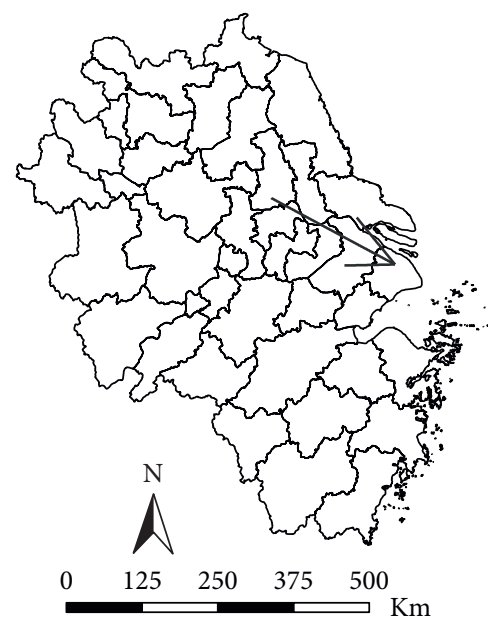

Branches (Unit: pcs)

- 1 - 30

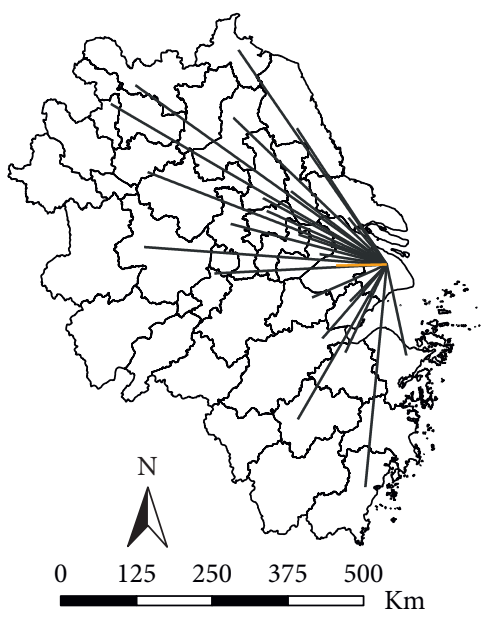

Branches (Unit: pcs)

- 1 - 30

- $31-300$

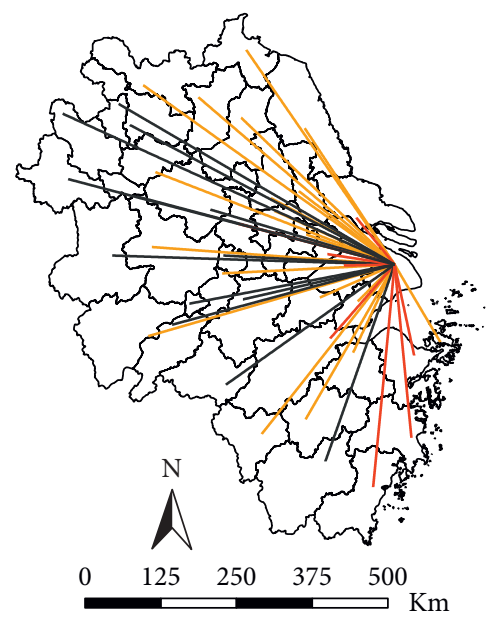

Branches (Unit: pcs)

- 1 - 30

- $31-300$

- $301-3000$ (a)

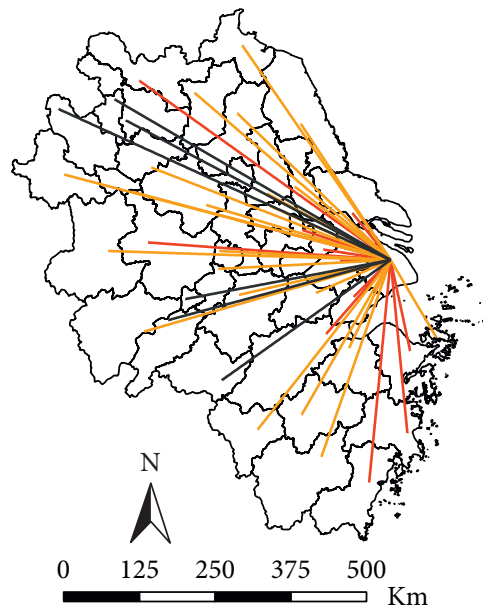

Branches (Unit: pcs)

- 1 - 30

- $31-300$

- $301-3000$

(d) (c)

(b)

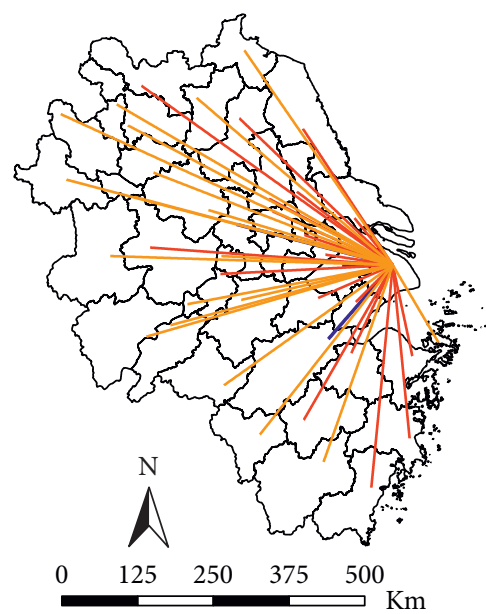

Branches (Unit: pcs)

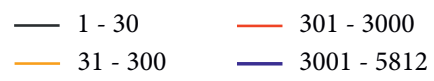

(e)

FIgURe 3: Headquarters-branch enterprise linkages between Shanghai and hinterland cities. (a) 1978. (b) 1992. (c) 2003. (d) 2009. (e) 2019.

enterprise branch linkages to Shanghai. In 2019, the total number of branches in the three cities accounted for nearly $40 \%$ of the total number of branches in the YRD.

4.1.2. Spatiotemporal Characteristics of Enterprise Investment Linkages. According to the classification of natural breaks in ArcGIS 10.3, the investment amount of enterprises can be divided into four types. These are low investments $(1-1000)$, medium investments (1001-1000000), high investments (1000001-1000000000), and superhigh investments (1000000001-1016156440). There is a significant difference in the amount of investment represented by each type (Figure 4, Tables 5-7).
Overall, Shanghai's enterprise investment in hinterland cities is concentrated in some cities (Figure 4). In terms of the different provinces, we have the following: (1) Enterprise investment in Jiangsu Province is mainly concentrated in economically developed southern Jiangsu. Nanjing, Suzhou, Wuxi, and Changzhou were the key invested cities in Jiangsu Province. Over the years, these four cities have been in the top five positions of the investment rankings, and their total investment in Jiangsu Province has remained above 80\%. (2) Enterprise investment in Zhejiang Province focuses on economic and characteristic resources. Shanghai's enterprise investments focused on two cities, Hangzhou and Ningbo. From 1978 to 2019, the total investment in the two cities 
TABLe 2: Proportion of headquarters-branch enterprise linkages in cities in Jiangsu Province.

\begin{tabular}{|c|c|c|c|c|c|}
\hline & $1978(\%)$ & $1992(\%)$ & $2003(\%)$ & $2009(\%)$ & $2019(\%)$ \\
\hline Nanjing & - & 10.99 & 19.26 & 20.62 & 18.80 \\
\hline Wuxi & - & 10.44 & 16.76 & 14.85 & 13.11 \\
\hline Xuzhou & - & 8.24 & 4.88 & 4.10 & 3.72 \\
\hline Changzhou & - & 6.59 & 5.21 & 4.98 & 6.48 \\
\hline Suzhou & 18.18 & 22.53 & 24.14 & 29.07 & 31.94 \\
\hline Nantong & 72.73 & 9.89 & 7.93 & 7.07 & 8.41 \\
\hline Lianyungang & - & 8.79 & 2.90 & 2.57 & 1.35 \\
\hline Huai'an & - & 0.55 & 2.57 & 2.15 & 2.02 \\
\hline Yancheng & - & 0.55 & 4.62 & 3.76 & 3.54 \\
\hline Yangzhou & 9.09 & 6.04 & 3.40 & 3.65 & 3.85 \\
\hline Zhenjiang & - & 6.04 & 3.79 & 2.85 & 2.80 \\
\hline Taizhou & - & 9.34 & 3.79 & 3.31 & 2.78 \\
\hline Suqian & - & - & 0.74 & 1.00 & 1.20 \\
\hline
\end{tabular}

TABle 3: Proportion of headquarters-branch enterprise linkages in cities in Zhejiang Province.

\begin{tabular}{|c|c|c|c|c|c|}
\hline & 1978 & $1992(\%)$ & $2003(\%)$ & $2009(\%)$ & $2019(\%)$ \\
\hline Hangzhou & - & 19.44 & 24.77 & 26.17 & 34.37 \\
\hline Ningbo & - & 36.11 & 20.16 & 24.21 & 21.41 \\
\hline Wenzhou & - & 2.78 & 11.86 & 9.93 & 9.27 \\
\hline Jiaxing & - & 2.78 & 8.24 & 9.87 & 8.68 \\
\hline Huzhou & - & 8.33 & 4.08 & 2.88 & 3.64 \\
\hline Shaoxing & - & 27.78 & 6.90 & 4.78 & 5.84 \\
\hline Jinhua & - & 2.78 & 4.08 & 4.61 & 5.75 \\
\hline Quzhou & - & - & 1.27 & 1.04 & 1.33 \\
\hline Zhoushan & - & - & 2.65 & 2.67 & 1.99 \\
\hline Taizhou & - & - & 15.03 & 12.90 & 6.55 \\
\hline Lishui & - & - & 0.95 & 0.94 & 1.17 \\
\hline
\end{tabular}

TABle 4: Proportion of headquarters-branch enterprise linkages in cities in Anhui Province.

\begin{tabular}{|c|c|c|c|c|c|}
\hline & 1978 & $1992(\%)$ & $2003(\%)$ & $2009(\%)$ & $2019(\%)$ \\
\hline Hefei & - & 17.65 & 33.97 & 38.94 & 43.30 \\
\hline Wuhu & - & 17.65 & 16.13 & 8.97 & 8.78 \\
\hline Bengbu & - & 23.53 & 8.54 & 6.24 & 5.29 \\
\hline Huainan & - & - & 5.69 & 5.55 & 3.73 \\
\hline Maanshan & - & - & 4.93 & 3.95 & 3.97 \\
\hline Huaibei & - & 41.18 & 3.80 & 1.60 & 1.88 \\
\hline Tongling & - & - & 1.52 & 2.28 & 2.05 \\
\hline Anqing & - & - & 7.40 & 5.86 & 4.28 \\
\hline Huangshan & - & - & 2.09 & 2.28 & 2.34 \\
\hline Chuzhou & - & - & 5.31 & 5.70 & 4.54 \\
\hline Fuyang & - & - & 5.31 & 4.56 & 5.40 \\
\hline Suzhou & - & - & 1.14 & 2.28 & 3.13 \\
\hline Liuan & - & - & 0.38 & 3.80 & 3.86 \\
\hline Bozhou & - & - & 0.19 & 1.98 & 2.49 \\
\hline Chizhou & - & - & 0.38 & 1.98 & 1.37 \\
\hline Xuancheng & - & - & 3.23 & 4.03 & 3.57 \\
\hline
\end{tabular}

remained above 55\% in Zhejiang Province. In other years, Shanghai also invested in other cities, such as Shaoxing (in 1992), Wenzhou (in 2009), and Jiaxing (in 2019), but the proportion of investment was lower than that seen in Hangzhou and Ningbo. (3) Enterprise investment in Anhui Province has gradually decentralized. The amount of Shanghai's investment in Hefei dropped sharply. From 1992 to 2019, the proportion of Shanghai's total investment in Hefei in Anhui Province decreased from 99.88\% to 26.23\%, making its proportion closer to that of Wuhu.
In terms of time, Shanghai's enterprise investment linkages in hinterland cities have become increasingly close and tend to increase in general (Figure 4). (1) During the period of the community economy, the investment scope of Shanghai enterprises expanded from two cities in 1978 to 25 in 1992. The investment scope was relatively scattered, and the main levels of investment seen were "low" and "medium" investments. (2) During the period of marketization, the investment scope of Shanghai enterprises expanded to all cities in the YRD. "Medium investment" cities accounted for 


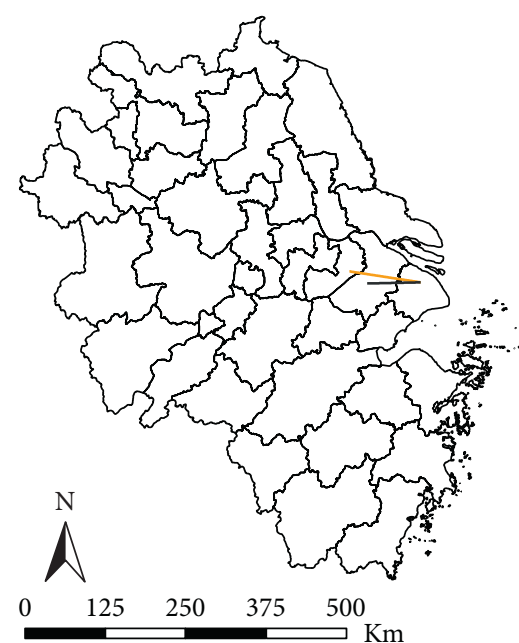

Investment (Unit: 10,000 Yuan)

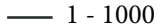

$-1001-1000000$

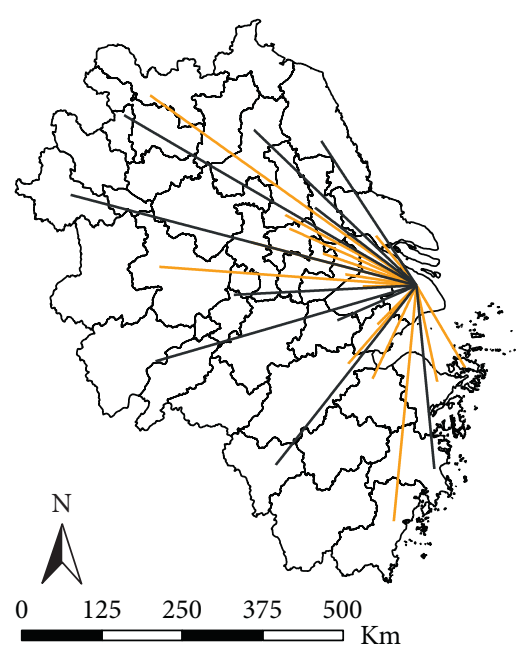

Investment (Unit: 10,000 Yuan)

- 1 - 1000

$-1001-1000000$

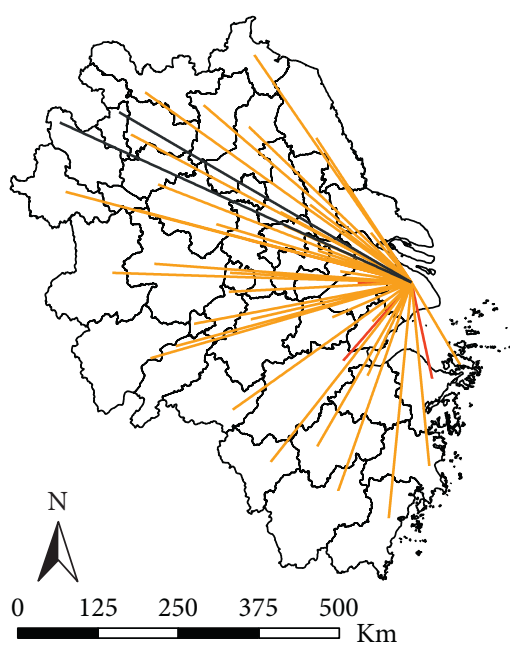

Investment (Unit: 10,000 Yuan)

- 1 - 1000

- $1001-1000000$

- $1000001-1000000000$

(c)

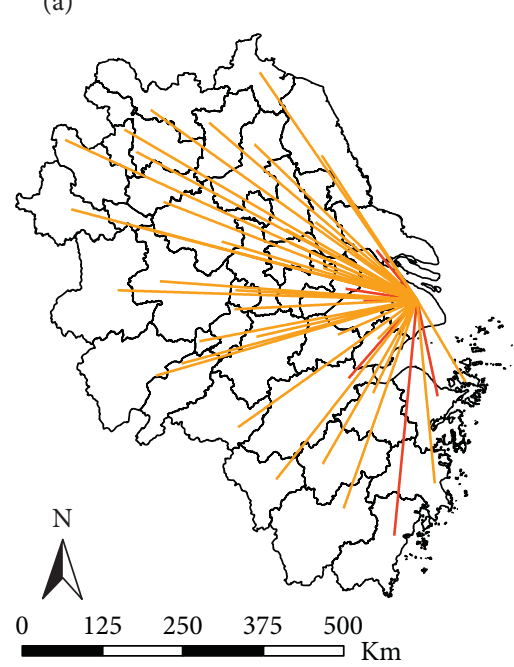

Investment (Unit: 10,000 Yuan)

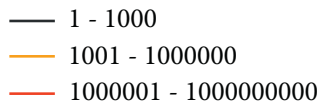

(b)

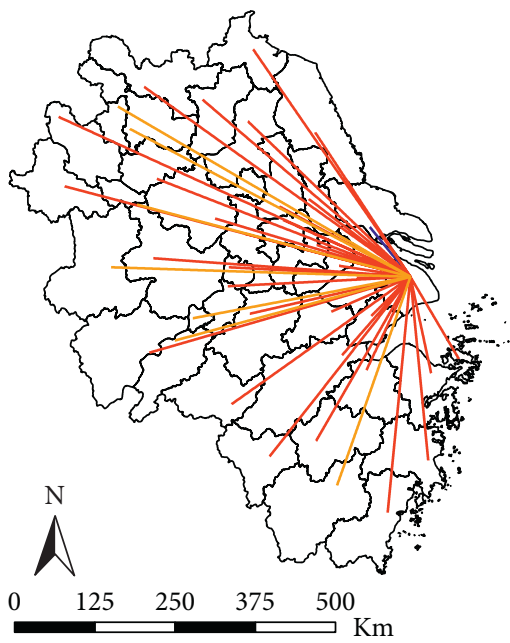

Investment (Unit: 10,000 Yuan)

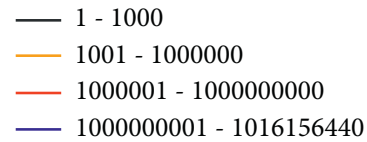

(e)

FIgUre 4: Enterprise investment linkages between Shanghai and hinterland cities. (a) 1978. (b) 1992. (c) 2003. (d) 2009. (e) 2019.

$85 \%$, and "high investment" cities accounted for $10 \%$. (3) During the period of globalization, the amount invested by Shanghai enterprises increased. The proportion of "high investment" cities increased slightly, reaching $17.50 \%$, and the rest were "medium investment" cities. (4) During the localization period, the investment linkages between Shanghai and its hinterland cities were upgraded and $80 \%$ of those cities reached "high investment" status. 
Table 5: Proportion of enterprise investment in cities in Jiangsu Province.

\begin{tabular}{|c|c|c|c|c|c|}
\hline & $1978(\%)$ & $1992(\%)$ & $2003(\%)$ & $2009(\%)$ & $2019(\%)$ \\
\hline Nanjing & - & 76.85 & 35.25 & 37.86 & 2.66 \\
\hline Wuxi & 96.73 & 2.24 & 5.05 & 11.04 & 1.13 \\
\hline Xuzhou & - & 1.06 & 1.81 & 1.88 & 0.32 \\
\hline Changzhou & - & 1.50 & 4.25 & 3.69 & 0.68 \\
\hline Suzhou & 3.27 & 16.36 & 44.55 & 27.58 & 3.91 \\
\hline Nantong & - & 0.64 & 1.21 & 7.74 & 89.20 \\
\hline Lianyungang & - & - & 0.46 & 1.50 & 0.18 \\
\hline Huai'an & - & 0.05 & 1.01 & 0.83 & 0.14 \\
\hline Yancheng & - & 0.00 & 0.47 & 1.70 & 0.44 \\
\hline Yangzhou & - & 0.85 & 4.39 & 2.47 & 0.34 \\
\hline Zhenjiang & - & 0.40 & 0.87 & 1.92 & 0.56 \\
\hline Taizhou & - & 0.04 & 0.59 & 1.50 & 0.33 \\
\hline Suqian & - & - & 0.10 & 0.30 & 0.11 \\
\hline
\end{tabular}

TABle 6: Proportion of enterprise investment in cities in Zhejiang Province.

\begin{tabular}{|c|c|c|c|c|c|}
\hline & 1978 & $1992(\%)$ & $2003(\%)$ & $2009(\%)$ & $2019(\%)$ \\
\hline Hangzhou & - & 25.01 & 36.99 & 42.56 & 29.71 \\
\hline Ningbo & - & 52.50 & 35.89 & 22.66 & 28.20 \\
\hline Wenzhou & - & 2.69 & 5.08 & 10.93 & 4.78 \\
\hline Jiaxing & - & 1.78 & 5.42 & 8.28 & 20.52 \\
\hline Huzhou & - & 0.09 & 5.76 & 4.35 & 3.60 \\
\hline Shaoxing & - & 15.71 & 2.91 & 3.20 & 3.88 \\
\hline Jinhua & - & - & 1.99 & 1.72 & 2.11 \\
\hline Quzhou & - & 0.01 & 0.26 & 0.80 & 0.77 \\
\hline Zhoushan & - & 2.16 & 4.13 & 3.76 & 3.52 \\
\hline Taizhou & - & 0.06 & 1.54 & 1.72 & 2.47 \\
\hline Lishui & - & - & 0.04 & 0.03 & 0.45 \\
\hline
\end{tabular}

Table 7: Proportion of enterprise investment in cities in Anhui Province.

\begin{tabular}{|c|c|c|c|c|c|}
\hline & 1978 & $1992(\%)$ & $2003(\%)$ & $2009(\%)$ & $2019(\%)$ \\
\hline Hefei & - & 99.88 & 55.36 & 46.61 & 26.23 \\
\hline Wuhu & - & 0.02 & 24.74 & 18.93 & 18.74 \\
\hline Bengbu & - & - & 1.30 & 1.91 & 4.16 \\
\hline Huainan & - & - & 0.58 & 0.78 & 2.30 \\
\hline Maanshan & - & - & 3.20 & 5.53 & 4.95 \\
\hline Huaibei & - & 0.05 & 0.01 & 0.45 & 2.37 \\
\hline Tongling & - & - & 0.40 & 0.46 & 1.77 \\
\hline Anqing & - & 0.02 & 0.69 & 1.05 & 2.98 \\
\hline Huangshan & - & - & 5.22 & 3.29 & 3.95 \\
\hline Chuzhou & - & - & 2.11 & 3.97 & 4.16 \\
\hline Fuyang & - & 0.03 & 2.62 & 1.04 & 2.61 \\
\hline Suzhou & - & - & 0.74 & 0.97 & 1.44 \\
\hline Liuan & - & - & 0.30 & 9.19 & 1.74 \\
\hline Bozhou & - & - & 0.03 & 1.95 & 5.25 \\
\hline Chizhou & - & - & 1.80 & 1.86 & 1.14 \\
\hline Xuancheng & - & - & 0.88 & 2.01 & 16.21 \\
\hline
\end{tabular}

\subsection{Results of Enterprise Linkages in the YRD}

4.2.1. Results of Headquarters-Branch Enterprise Linkages. According to Table 8, the overall comparison of the influencing factors of headquarters-branch enterprise linkages in the three provinces shows that capital status (DP) and communication facilities status (TS) had a significant positive impact on the establishment of enterprise branches. This shows that economic strength and the degree of informatization are the key factors that affect whether Shanghai sets up an enterprise branch in the city. Jiangsu Province and Zhejiang Province/Anhui Province have different demands for labor reserves. Jiangsu places more emphasis on the total amount of labor, while Zhejiang and 
Anhui place more emphasis on the distribution density of labor capital. This may be because Jiangsu pays more attention to the distribution of labor on a larger scale, and the establishment of branch connections by enterprises focuses more on prefecture-level city units, while Zhejiang and Anhui Province pay more attention to labor in small-scale areas. The lower the industrialization level of Zhejiang and Anhui Provinces, the more the branches set up by local enterprises. This may be because places with a higher proportion of the tertiary industry are more attractive for enterprises to set up branches. Compared with Zhejiang, Shanghai pays more attention to the local market capacity when setting up business branches in Jiangsu and Anhui, which shows the positive significance of urban residents' consumption power for business branches. For provinces that are less economically underdeveloped, the establishment of branches by enterprises is more inclined to be in areas with high levels of urbanization.

In Jiangsu Province, capital status (DP) and communication facility status (TS) had a significant positive impact on enterprise branch establishment. Suzhou and Nanjing are the cities where Shanghai has the most branches in Jiangsu Province. Suzhou has strong economic strength and is close to Shanghai. It can quickly pass through the construction of national economic development zones and provincial development zones and build advanced manufacturing bases around Shanghai, forming a close connection with the city. Large-scale infrastructure construction and industrial clusters have attracted many people to work. The rapid development and upgrading of the industry have laid a good foundation for the establishment of branch enterprises in Shanghai. With a closer connection with Shanghai in the later period, relying on the overflow of resources in Shanghai, Suzhou's economic level and the level of supporting infrastructure have been continuously improved, forming a virtuous economic cycle [41]. Relying on the hightech development zone established in the early years, Nanjing has fully enhanced the competitive advantages of leading industries such as petrochemicals, automobile manufacturing, and electronic complete machines and components and formed an industrial scale. The development of the industry has promoted the accumulation of considerable laborers, and Nanjing has also continued to attract Shanghai to set up enterprise branches. Capital input (FAI) had a significant negative impact on the establishment of enterprise branches. A possible reason may be that the market-oriented reform in Jiangsu Province was early, and the economically developed regions attracted many people based on their own advantages, forming an intensive development path. Per capita investment in fixed assets is relatively small in economically developed areas, so Shanghai's enterprise branch establishments choose cities with low capital input. This indicates that Shanghai's establishment of branch enterprises in Jiangsu Province tended to be concentrated in areas with affluent residents and complete infrastructure and that enterprise branch establishment did not depend on capital investment.

In Zhejiang Province, communication facility status (TS), capital status (DP), labor abundance (PD), and traffic accessibility (HM) all had positive impacts on enterprise branch establishment. However, the industrialization level (IDU) had a significant negative correlation with it. This indicates that the establishment of branch enterprises in Shanghai in Zhejiang Province tended to be in cities with well-developed infrastructure, high levels of residential income, and sufficient labor and cities which were not dominated by industrial enterprises. Relying on the advantages of the provincial capital, Hangzhou possesses economic advantages and labor resources. From 2009 to 2019, Shanghai set up more enterprise branches in Hangzhou than Ningbo. During this period, Hangzhou prioritized the service industry and digital economy to drive the development of tertiary industry as its main goal, actively undertaking the international service industry, and the proportion of the secondary industry continued to decline. In 2014, the Hangzhou Municipal Party Committee deliberated and approved the "Several Opinions on Accelerating the Development of the Information Economy" and created a strategic plan for the development of the information economy. Hangzhou officially launched the "No. 1 Project" of "Developing the Information Economy and Promoting Smart Applications." After that, Hangzhou used the strength of the whole city to promote the priority development of the information economy. In 2018, the proportion of Hangzhou's secondary industry dropped to $31.7 \%$ and the proportion of tertiary industry reached nearly $66.2 \%$. The development of the tertiary industry has promoted the improvement of infrastructure facilities and attracted a large flow of labor. Ningbo has always set industrial development as its goal. In the early years, Ningbo relied on the advantages of its seaports to vigorously promote economic development and formed a strong enterprise relationship with Shanghai. Currently, the Ningbo Municipal Government has determined the strategic goal of building a strong industrial city, and the secondary industry accounts for more than $50 \%$ of its economy in Ningbo. When the economy enters the advanced stage, the higher the level of industrialization, the lower the proportion of the tertiary industry and the lesser the advantage to the city when it establishes a branch in Shanghai.

In Anhui Province, marketization (FRE), communication facilities (TS), labor abundance (PD), urbanization (UR), capital status (DP), and market capacity (CGP) had a positive and significant impact on the establishment of enterprise branches. Traffic accessibility (HM) was a necessary element for the establishment of enterprise branches, but it was not a key element. However, the industrialization level (IDU) had a significant negative impact on enterprise branch establishment. In general, Shanghai's establishment of branch companies in Anhui mainly considers the city's openness, economic strength, and labor level, and it prefers cities that do not rely on the secondary industry. Anhui Province is a relatively underdeveloped area, and many regions in the province are still in the initial stage of urbanization development, with low levels of urbanization and marketization. Problems such as the large proportion of the agricultural population and the shortage of urban labor have restricted the development of cities. Anhui Province concentrates its 
TABLE 8: Regression results of headquarters-branches enterprise linkages.

\begin{tabular}{lcccc}
\hline Independent variable & YDR & Jiangsu & Zhejiang & Anhui \\
\hline ln FAI & $-0.044(-0.368)$ & $-0.643^{* * *}(-2.915)$ & $-0.091(-0.839)$ & $0.172(1.121)$ \\
ln LR & $0.337^{* * *}(2.825)$ & $0.323^{*}(1.940)$ & $0.070(1.444)$ & $0.137(0.797)$ \\
$\ln$ UR & $0.650^{* * *}(4.212)$ & $0.514(0.928)$ & $0.096(0.894)$ & $0.589^{* * *}(2.860)$ \\
ln IDU & $-0.666(-1.617)$ & $0.127(0.171)$ & $-0.351^{* * *}(-3.510)$ & $-2.143^{* * *}(-5.608)$ \\
$\ln$ FRE & $1.311^{* * *}(3.693)$ & $-0.588(-0.712)$ & $-0.053(-0.772)$ & $2.054^{* * *}(5.044)$ \\
$\ln$ DP & $0.606^{* * *}(3.320)$ & $1.126^{* * *}(4.176)$ & $1.127^{* * *}(5.692)$ & $0.367^{* *}(2.294)$ \\
ln PD & $0.408^{* * *}(3.032)$ & $0.104(0.164)$ & $0.640^{* * *}(4.954)$ & $0.460^{* * *}(4.323)$ \\
$\ln$ CGP & $0.234(1.167)$ & $0.448^{*}(1.763)$ & $0.081(0.302)$ & $0.522^{* *}(2.191)$ \\
ln HM & $0.282^{* *}(2.190)$ & $0.152(0.508)$ & $0.249^{* * *}(4.029)$ & $0.287^{*}(1.804)$ \\
$\ln$ TS & $0.044^{* * *}(3.143)$ & $0.053^{* * *}(2.954)$ & $0.443^{* * *}(6.204)$ & $0.354^{* * *}(4.903)$ \\
Constant & $-10.298^{* * *}(-6.208)$ & $-9.641^{* *}(-2.321)$ & $-13.775^{* * *}(-12.318)$ & $-7.917^{* * *}(-5.284)$ \\
$N$ & 40 & 13 & 11 & 16 \\
$R^{2}$ & 0.893 & 0.898 & 0.954 & 0.992 \\
\hline
\end{tabular}

Note: the symbols ${ }^{*},{ }^{* *}$, and ${ }^{* * *}$ represent the significance levels of $10 \%, 5 \%$, and $1 \%$, respectively; the values in parentheses are the corresponding $t$-values.

advantageous resources in the provincial capital city Hefei through infrastructure construction and the provision of public products. After the reform of the tax-sharing system, local governments' dependence on local revenues has increased, which has weakened the ability of local governments to redistribute resources to achieve fairness goals [42]. Hefei's first position in Anhui Province has been continuously strengthened. It has advantages in marketization, infrastructure, and labor and has become an important city in the central region to undertake the gradient transfer of industries in the developed coastal areas of China.

\subsubsection{Results of Enterprise Investment Linkages.} According to Table 9, comparing the factors influencing enterprise investment in the three provinces, capital status (DP) had a positive impact on Shanghai's enterprise investment in all the three provinces. In Jiangsu and Zhejiang Provinces, the higher the market capacity, the more they can attract enterprise investment. This may be because Shanghai's investment in these two provinces relies on the support of their local high-consumption markets, while its investment in Anhui Province does not. The relationship between enterprise investment in Zhejiang and the level of industrialization is inversely correlated, but the investment of enterprises in Jiangsu and Anhui Provinces is positively correlated with the level of industrialization. A possible reason for this may be that Shanghai's investment in Zhejiang Province is biased toward cities whose industrial industries have transformed into tertiary industries. Enterprise investment in Jiangsu Province depends on the construction of communication infrastructure, while in Anhui Province, it is more inclined to areas with underdeveloped communication infrastructure. This may be related to the difference between the advantageous industries in Jiangsu and Anhui. Shanghai is more willing to invest in places with good communication infrastructure in Jiangsu Province, while investment in Anhui Province relies on its natural base advantages and its information infrastructure tends to be imperfect. The capital investment (FAI) and investment choices of enterprises in Jiangsu and Zhejiang Provinces had a significant negative impact. A possible reason may be that Shanghai's choice of investment locations in Jiangsu and Zhejiang Provinces is biased toward cities with earlier market development.

In Jiangsu Province, capital investment (FAI) had a significant negative correlation with enterprise investment. Capital status (DP), labor input (LR), communication facility status (TS), industrialization level (IDU), and market capacity (CGP) were positively correlated with enterprise investment. This shows that investors in Jiangsu were more inclined to choose cities with economic strength, high income levels, and the strong consumption power of residents. The status of the urban industry and the adequacy of labor were also considerations that supported investment choices. Since the 1970s, southern Jiangsu has accumulated wealth through the development of townships and village enterprises. It has a strong economy, high population density, and complete support facilities, which give southern Jiangsu a competitive advantage in the YRD. The convenient transportation linkages between southern Jiangsu and Shanghai have encouraged the transfer of Shanghai's traditional manufacturing industries to southern Jiangsu. Many iron and steel, metallurgy, building material, petrochemical, and energy industries have been established along the transportation line, that is, the Yangtze River. Urban infrastructure construction guaranteed the expansion and development of enterprises. In Kunshan, Suzhou, multiple small- and medium-sized foreign companies in the IT industry have gathered. Six of Taiwan's top ten notebook computer manufacturers gathered and brought hundreds of Taiwanese-supporting enterprises to settle in Kunshan, rendering the area the world's largest notebook computer production base. Due to the existence of economies of scale and scope, specialized regions have further attracted related enterprises to join, forming an evolutionary process of path dependence [43], and perfect basic supporting facilities can provide a guarantee for industrial expansion. With the improvement of the market mechanism, the establishment of branches of enterprises in Shanghai no longer relies on the promotion of the government, instead it depends more on the market promotion. 
TABLE 9: Regression results of enterprise investment.

\begin{tabular}{lcccc}
\hline Independent variable & YDR & Jiangsu & Zhejiang & Anhui \\
\hline ln FAI & $0.257(1.272)$ & $-0.932^{* * *}(-3.219)$ & $-0.583^{* *}(-2.626)$ & $-0.221(-0.339)$ \\
ln LR & $0.411^{* *}(2.079)$ & $0.567^{* * *}(2.930)$ & $0.071(0.622)$ & $1.461^{*}(2.002)$ \\
ln UR & $0.664^{* *}(2.575)$ & $0.008(0.013)$ & $0.236(1.397)$ & $0.367(0.418)$ \\
ln IDU & $0.241(0.346)$ & $2.109^{* *}(2.150)$ & $-0.536^{* * *}(-3.452)$ & $3.949^{* *}(2.429)$ \\
$\ln$ FRE & $1.280^{* *}(2.130)$ & $-1.348(-1.223)$ & $-0.296^{*}(-1.796)$ & $1.940(1.121)$ \\
ln DP & $1.128^{* * *}(3.639)$ & $2.082^{* * *}(5.753)$ & $1.426^{* * *}(4.512)$ & $1.183^{*}(1.738)$ \\
ln PD & $0.281(1.254)$ & $-0.081(-0.118)$ & $1.098^{* * *}(4.280)$ & $-0.015(-0.034)$ \\
ln CGP & $0.157(0.462)$ & $0.715^{* *}(2.035)$ & $0.833^{*}(1.845)$ & $0.461(0.455)$ \\
ln HM & $0.239(1.112)$ & $0.603^{*}(1.864)$ & $0.054(0.388)$ & $0.352(0.521)$ \\
$\ln$ TS & $-0.002(-0.078)$ & $0.067^{* * *}(2.728)$ & $-0.087(-0.774)$ & $-1.225^{* * *}(-3.990)$ \\
Constant & $-12.461^{* * *}(-4.423)$ & $-20.667^{* * *}(-3.903)$ & $-9.324^{* * *}(-4.164)$ & $-24.407^{* * *}(-3.830)$ \\
$N$ & 40 & 13 & 11 & 16 \\
$R^{2}$ & 0.884 & 0.937 & 0.927 & 0.916 \\
\hline
\end{tabular}

Note: the symbols ${ }^{*},{ }^{* *}$, and ${ }^{* * *}$ represent the significance levels of $10 \%, 5 \%$, and $1 \%$, respectively; the values in parentheses are the corresponding $t$-values.

In Zhejiang Province, capital status (DP), labor abundance (PD), and market capacity (CGP) had positive effects on enterprise investment. However, the industrialization level (IDU) had a significant negative impact on enterprise investment. Capital investment (FAI) and marketization (FRE) had a negative effect on enterprise investment, but they were not decisive factors. This shows that in Zhejiang Province, Shanghai investors were more inclined to choose hinterland cities with strong economic growth among residents, high residential spending power, and dense populations as investment locations. The tertiary industry-led cities represented by Hangzhou are hot cities for investment in Shanghai. In addition, many cities in Zhejiang have formed an industrial structure dominated by light industry through the development of family workshops and family factories. Due to the promotion of industrialization in these cities over the years, the proportion of tertiary industries has continuously increased and their urban service capabilities have improved. The establishment of a characteristic market can form a competitive advantage nationwide and has a profitable and abundant labor market. It has an absolute advantage in undertaking Shanghai's capacity overflow. The development of clothing and consumer goods as the leading industries also depends on the residents' high consumption power. Examples of this include the Yiwu small commodity market, Haining leather market, and Shaoxing textile market. Nowadays, the Shaoxing textile market is developing rapidly, attracting a large amount of investment and transforming into the professional textile wholesale market with the largest scale, the highest turnover and the most variety in Asia. The textile and garment industry clusters in Jiashan, Zhejiang, and other places have developed rapidly during this period, and the employment density of the textile and garment manufacturing industry has also increased significantly.

In Anhui Province, industrial level (IDU), labor input (LR), and capital status (DP) had positive effects on enterprise investment choices, but communication facility status (TS) had a significant negative correlation with enterprise investment. This indicates that Shanghai's investment in Anhui Province tended to be in cities with immature infrastructure. The economic strength of Anhui Province does not have comparative advantages in the YRD, but ecological environment resources and agricultural industry are some of this province's advantages. Due to the slow development of Anhui's urbanization process, cities that developed by relying on ecological industries are still in the development stage. These areas often have insufficient infrastructure and poor infrastructure facilities. Xuancheng is one of the cities with an excellent ecological environment in Anhui Province, with a forest coverage rate of $59.34 \%$. There are four national ecological demonstration areas, one national nature reserve, and three provincial nature reserves. Outstanding location advantages and good natural conditions provide a strong guarantee for the development of modern agriculture. Xuancheng has become an important production and supply base for grain, oil, tea, poultry, and forest products in the YRD. The agricultural value of Xuancheng has significant advantages. In 2019, Shanghai Brightdairy Dairy Co., Ltd. cooperated with Xuancheng to invest 6 billion yuan to build a food production and processing base.

\section{Conclusion and Discussion}

This study used headquarters-branch enterprise linkage and enterprise investment data from 1978 to 2019 to explore the enterprise linkages between Shanghai and its hinterland cities in the YRD. It expands the time range of the research area and improves the limitations of short and incomplete data in previous studies. At the same time, it also innovatively introduced a number of relevant factors, which further analyzed the influencing factors of the internal evolution mechanism of the metropolitan area and enriched our understanding of the temporal and spatial evolution of the core-peripheral structure of the YRD. The main conclusions of this study are as follows:

(1) In the YRD, the headquarters-branch enterprise linkages between Shanghai and hinterland cities have gradually become polarized, and they are increasingly concentrated in large cities with strong economic strength. Suzhou, Hangzhou, and Nanjing have become the cities with the highest number of 
branches. In terms of different provinces, the headquarters-branch linkages between Jiangsu and Shanghai exhibit "dual polarization" characteristics. Suzhou and Nanjing have the highest number of branches in Jiangsu. The headquarters-branch linkages between Zhejiang and Shanghai demonstrate "core replacement" characteristics. Hangzhou has gradually replaced Ningbo as the city with the most branches in Zhejiang. The headquarters-branch linkages between Anhui and Shanghai manifest significant "single-point polarization" characteristics, and Hefei's position in Anhui Province is prominent. The city's economic strength has become a key factor in Shanghai's choice of whether to establish a branch location for a company. Based on the regression results, in the three provinces of Jiangsu, Zhejiang, and Anhui, the capital status (DP) and the status of communication facilities (TS) positively impacted the construction of enterprise branches. The main reason is that cities with economic foundations can quickly respond to market development trends and provide construction capital to undertake enterprise spillovers in the central city.

(2) Enterprise investment linkages between Shanghai and its hinterland cities are getting closer, but the key cities for investment in each province are different. In the choice of investment locations for hinterland cities, Shanghai prefers cities that can represent the characteristics of the province and focus more on considering the city's comparative advantages. Enterprise investment in Jiangsu Province is mainly concentrated in economically developed southern Jiangsu. Nanjing, Suzhou, Wuxi, and Changzhou are the core investment cities in Jiangsu. Enterprise investment in Zhejiang Province focuses on economically developed regions or cities with characteristic resources. The core investment cities mainly include Hangzhou and Ningbo. Enterprise investment in Anhui Province has been gradually decentralized, and the amount of Shanghai's investment in Hefei has dropped sharply. Based on the regression results of enterprise investment linkages, the higher the market capacity in Jiangsu and Zhejiang provinces, the more it can attract enterprise investment. Enterprise investment in Jiangsu Province depends on the construction of communication infrastructure, while enterprise investment in Anhui Province, on the contrary, is more inclined to areas with underdeveloped communication infrastructure.

Research is of great significance to the future development of metropolitan areas. Research has shown that the enterprise branch linkages of the central city and the peripheral cities in metropolitan areas are increasingly concentrated in economically developed areas and their radiating effect on other cities is weaker. This view is consistent with the conclusions of Hymer who believe that enterprise locations tend to be concentrated in a few central cities [44]. This shows that the relationship between enterprises is based on economic relevance rather than geographic proximity [45]. This process often leads to greater development in already affluent areas, making the gap between rich and poor areas larger and larger [46]. Therefore, in order to reduce the gap within the metropolitan areas, the government can increase investment in infrastructure in economically backward areas in terms of policies and systems to provide support for undertaking the overflow of resources in central cities. In terms of enterprise investment, there are significant differences in the regression models of different provinces, reflecting the different ways of spreading Shanghai to different provinces. The characteristic industry of the city has the effect of attracting investment from the central city.

The interenterprise investment has the phenomenon of linkage in the same region, which will promote the phenomenon of investment convergence in the investment of enterprises in the same region. Therefore, cities need to fully integrate their own advantageous resources in planning and give full play to the natural geographical environment, advantageous industrial industries, and other supporting factors. Cities should seize the strategic opportunity for the integrated development of the Yangtze River Delta, strengthen cooperation with central cities and internal cooperation, strengthen the leading and radiating demonstration role of prominent industries, and use the contextual and spillover effects of leading industries to attract central cities to establish themselves. They must invest in links to promote their own economic development.

Due to data acquisition and space limitations, this study still has room for improvement. For example, the selected influencing factor data were not complete due to incomplete data of earlier years, so it was impossible to conduct a more detailed discussion of influencing factors by time. Due to space restrictions, no further detailed research has been conducted on the influencing factors of each city. More refined analysis can provide detailed support for our research. This article needs to further expand the data mining in this field in the future.

\section{Data Availability}

The enterprise linkage data used to support the findings were supplied by the enterprise registration information of the State Administration for Industry and Commerce (http:// www.gsxt.gov.cn).

\section{Disclosure}

The funding sources had no role in the study design, data collection, analysis, interpretation, or writing of this manuscript.

\section{Conflicts of Interest}

The authors declare that there are no conflicts of interest.

\section{Acknowledgments}

This research was supported by the National Natural Science Foundation of China (Nos. 52078245 and 41971162). 


\section{References}

[1] C. L. Ross, Megaregions: Planning for Global Competitiveness, Island Press, Washington, DC, USA, 2009.

[2] J. Gottmann, "Megalopolis or the urbanization of the northeastern seaboard," Economic Geography, vol. 33, no. 3, pp. 189-200, 1957.

[3] F. van Oort, M. Burger, and O. Raspe, "On the economic foundation of the urban network paradigm: spatial integration, functional integration and economic complementarities within the Dutch randstad," Urban Studies, vol. 47, no. 4, pp. 725-748, 2010.

[4] N. Brenner and N. Theodore, "Cities and the geographies of "actually existing neoliberalism"," Antipode, vol. 34, no. 3, pp. 349-379, 2002.

[5] W. Anderson, Economic Geography, Routledge, New York, NY, USA, 2012.

[6] J. V. Beaverstock, M. A. Doel, P. J. Hubbard, and P. J. Taylor, "Attending to the world: competition, cooperation and connectivity in the world city network," Global Networks, vol. 2, no. 2, pp. 111-132, 2002.

[7] R. Yang, J. Zhanga, Q. Xub, and X. Luo, "Urban-rural spatial transformation process and influences from the perspective of land use: a case study of the Pearl River Delta Region," Habitat International, vol. 104, Article ID 102234, 2020.

[8] L. Zhou, X. Dang, H. Mu, B. Wang, and S. Wang, "Cities are going uphill: slope gradient analysis of urban expansion and its driving factors in China," The Science of the Total Environment, vol. 775, Article ID 145836, 2021.

[9] A. G. Champion, "A changing demographic regime and evolving poly centric urban regions: consequences for the size, composition and distribution of city populations," Urban Studies, vol. 38, no. 4, pp. 657-677, 2001.

[10] Z. P. Neal, "From central places to network bases: a transition in the U.S. Urban hierarchy, 1900-2000," City \& Community, vol. 10, no. 1, pp. 49-75, 2011.

[11] M. Castells, The Rise of Network Society, Blackwell, Oxford, UK, 1996.

[12] J. V. Beaverstock, R. G. Smith, and P. J. Taylor, "World-city network: a new m," Annals of the Association of American Geographers, vol. 90, no. 1, pp. 123-134, 2000.

[13] P. J. Taylor, "Specification of the world city network," Geographical Analysis, vol. 33, no. 2, pp. 181-194, 2001.

[14] P. J. Taylor, World City Network: A Global Urban Analysis, Routledege, New York, NY, USA, 2004.

[15] P. J. Taylor, M. Hoyler, and R. Verbruggen, "External urban relational process: introducing central flow theory to complement central place theory," Urban Studies, vol. 47, no. 13, pp. 2803-2818, 2010.

[16] M. C. Mahutga, fnm Xiulian Ma, D. A. Smith, and M. Timberlake, "Economic globalisation and the structure of the world city system: the case of airline passenger data," Urban Studies, vol. 47, no. 9, pp. 1925-1947, 2010.

[17] W. Zhang and B. Derudder, "Approximating actual flows in physical infrastructure networks: the case of the Yangtze River Delta high-speed railway network," Bulletin of Geography. Socio-Economic Series, vol. 31, no. 31, pp. 145-160, 2016.

[18] X. Liu, B. Derudder, and K. Wu, "Measuring polycentric urban development in China: an intercity transportation network perspective," Regional Studies, vol. 50, no. 8, pp. 1302-1315, 2016.

[19] G. Krings, F. Calabrese, C. Ratti, and V. D. Blondel, "Urban gravity: a model for inter-city telecommunication flows,"
Journal of Statistical Mechanics: Theory and Experiment, vol. 2009, 2009.

[20] P.-A. Laharotte, R. Billot, E. Come, L. Oukhellou, A. Nantes, and N.-E. El Faouzi, "Spatiotemporal analysis of Bluetooth data: application to a large urban network," IEEE Transactions on Intelligent Transportation Systems, vol. 16, no. 3, pp. 1439-1448, 2015.

[21] Y. Li and N. A. Phelps, "Articulating China's science and technology: knowledge collaboration networks within and beyond the Yangtze River Delta megalopolis in China," Chinese Geographical Science, vol. 28, no. 2, pp. 247-260, 2018.

[22] Y. Li and N. A. Phelps, "Knowledge polycentricity and the evolving Yangtze River Delta megalopolis," Regional Studies, vol. 51, no. 7, pp. 1035-1047, 2017.

[23] M. Zhao, X. Liu, B. Derudder, Y. Zhong, and W. Shen, "Mapping producer services networks in mainland Chinese cities," Urban Studies, vol. 52, no. 16, pp. 3018-3034, 2015.

[24] B. Derudder, Z. Cao, X. Liu et al., "Changing connectivities of Chinese cities in the world city network, 2010-2016," Chinese Geographical Science, vol. 28, no. 2, pp. 183-201, 2018.

[25] B. Derudder, X. Liu, C. Kunaka, and M. Roberts, "The connectivity of South Asian cities in infrastructure networks," Journal of Maps, vol. 10, no. 1, pp. 47-52, 2014.

[26] P. J. Taylor, B. Derudder, M. Hoyler, and P. Ni, "New regional geographies of the world as practised by leading advanced producer service firms in 2010," Transactions of the Institute of British Geographers, vol. 38, no. 3, pp. 497-511, 2013.

[27] F. Pan, W. Bi, J. Lenzer, and S. Zhao, "Mapping urban networks through inter-firm service relationships: the case of China," Urban Studies, vol. 54, no. 16, pp. 3639-3654, 2017.

[28] B. Derudder and P. Taylor, "Change in the world city network, 2000-2012," The Professional Geographer, vol. 68, no. 4, pp. 624-637, 2016.

[29] T. Zilai and L. Tao, "A comparative analysis of urban system in the Yangtze Delta Region and the Middle Yangtze Region: an approach of firm-based interlocking network," Urban Planning Forum, vol. 2, pp. 24-31, 2014.

[30] J. Y. Lu, D. Sun, J. Yu, J. Li, and F. Niu, "Local versus nonlocal enterprise linkages of global cities: a comparison between beijing and Shanghai, China," Complexity, vol. 2020, Article ID 8918534, 13 pages, 2020.

[31] J. Salder, "The networked economy of firms in city-region peripheries," European Urban and Regional Studies, vol. 28, pp. 195-212, 2020.

[32] A. G. Yeh, F. F. Yang, and J. Wang, "Producer service linkages and city connectivity in the mega-city region of China: a case study of the Pearl River Delta," Urban Studies, vol. 52, no. 13, pp. 2458-2482, 2015.

[33] X. Zhang, Q.-e. Guo, D. M.-w. Cheung, and T. Zhang, "Evaluating the institutional performance of the Pearl River Delta integration policy through intercity cooperation network analysis," Cities, vol. 81, pp. 131-144, 2018.

[34] E. Meijers, "From central place to network model: theory and evidence of a paradigm change," Tijdschrift voor Economische en Sociale Geografie, vol. 98, no. 2, pp. 245-259, 2007.

[35] Y. D. Wei, "Decentralization, marketization, and globalization: the triple processes underlying regional development in China," Asian Geographer, vol. 20, no. 1-2, pp. 7-23, 2001.

[36] Y. D. Wei, "Spatiality of regional inequality," Applied Geography, vol. 61, pp. 1-10, 2015.

[37] G. Li and C. Fang, "Spatial econometric analysis of urban and county-level economic growth convergence in China," International Regional Science Review, vol. 41, no. 4, pp. 410447, 2018. 
[38] A. Frenkel, "Why high-technology firms choose to locate in or near metropolitan areas," Urban Studies, vol. 38, no. 7, pp. 1083-1101, 2001.

[39] P. Guimaraes, O. Figueiredo, and D. Woodward, "Industrial location modeling: extending the random utility framework," Journal of Regional Science, vol. 44, no. 1, pp. 1-20, 2004.

[40] Z. Xuebo, Y. Wei, Z. Yali, S. Jinping, and W. Zhenbo, "Spatiotemporal differentiation and its influencing factors ofregional economic growth in Beijing-Tianjin-Hebei region," Acta Geographica Sinica, vol. 73, no. 10, pp. 1985-2000, 2018.

[41] L. Zhou, X. Dang, Q. Sun, and S. Wang, "Multi-scenario simulation of urban land change in Shanghai by random forest and CA-Markov model," Sustainable Cities and Society, vol. 55, Article ID 102045, 2020.

[42] F. H. F. Liao and Y. D. Wei, "Dynamics, space, and regional inequality in provincial China: a case study of Guangdong province," Applied Geography, vol. 35, no. 1-2, pp. 71-83, 2012.

[43] R. Martin and P. Sunley, "Path dependence and regional economic evolution," Journal of Economic Geography, vol. 6, no. 4, pp. 395-437, 2006.

[44] S. Hymer, The Multinational Corporation and the Law of Uneven Development: Perspectives on World Politics, Routledge, London, UK, 2006.

[45] P. Marek, M. Titze, C. Fuhrmeister, and U. Blum, "R\&D collaborations and the role of proximity," Regional Studies, vol. 51, no. 12, pp. 1761-1773, 2017.

[46] E. Wang, "Fiscal decentralization and revenue/expenditure disparities in China," Eurasian Geography and Economics, vol. 51, no. 6, pp. 744-766, 2010. 